\title{
Understanding Caregivers' Intentions for their Child to Walk to School: Further Application of the Theory of Planned Behavior
}

\author{
Dr. Lisa Schuster ${ }^{1 *}$ \\ Social Marketing @ Griffith, Griffith Health Institute, Griffith University \\ 170 Kessels Road, Nathan, 4111, Queensland \\ Email: 1.schuster@griffith.edu.au \\ Phone: +61 737357577 \\ Dr. Krzysztof Kubacki ${ }^{2}$ \\ Social Marketing @ Griffith, Griffith Health Institute, Griffith University \\ 170 Kessels Road, Nathan, 4111, Queensland \\ Email: k.kubacki@griffith.edu.au \\ Phone: +61 737356498 \\ Professor Sharyn Rundle-Thiele ${ }^{3}$ \\ Social Marketing @ Griffith, Griffith Health Institute, Griffith University \\ 170 Kessels Road, Nathan, 4111, Queensland \\ Email: s.rundle-thiele@griffith.edu.au \\ Phone: +61 737356446
}

This manuscript has not been published elsewhere and it has not been submitted simultaneously for publication elsewhere.

\footnotetext{
*Corresponding author

${ }^{1}$ Dr Lisa Schuster is a Research Fellow with Social Marketing @ Griffith with an interest in understanding and influencing initial and sustained healthy behavior change. She has published her research in the European Journal of Marketing, in scholarly books and in international and national peer-reviewed conferences, where she has received two best paper awards.

${ }^{2}$ Dr Krzysztof Kubacki is a Social Marketing Research Practice Fellow (VicHealth) and a Senior Lecturer in Marketing at Griffith University. Weaved throughout his research is an interest in the relationship between social marketing and consumer culture, with his most recent work focusing on alcohol consumption among young people and increasing physical activity among children and adults.

${ }^{3}$ Professor Sharyn Rundle-Thiele leads Social Marketing @ Griffith (www.griffith.edu.au/social-marketing) and is Editor of the Journal of Social Marketing. Sharyn's research focuses on behavior change and is widely published. She currently serves as an advisor on a diverse range of social marketing projects. Her current projects include changing adolescent attitudes towards drinking alcohol (see http://gameon.rcs.griffith.edu.au/) and increasing healthy eating and physical activity to combat obesity.
} 
Theory of Planned Behavior: Predicting Walking to School

\title{
Understanding Caregivers' Intentions for their Child to Walk to School: Further Application of the Theory of Planned Behavior
}

\begin{abstract}
Increases in childhood obesity have coincided with declines in active transportation to school. This research builds on largely atheoretical extant literature examining factors that influence walk to school behavior through application of the Theory of Planned Behavior (TPB). Understanding caregivers’ decision for their child to walk to/from school is key to developing interventions to promote this cost-effective and accessible health behavior. The results from an online survey of 512 caregivers provide support for the TPB, highlighting the important role of subjective norms. This suggests marketers should nurture caregivers' perception that important others, such as friends, approve of walking to school.
\end{abstract}

Keywords: Theory of Planned Behavior, walking, children, obesity, active transportation, social marketing 
Theory of Planned Behavior: Predicting Walking to School

\section{Introduction}

The rising rate of childhood obesity is a public health crisis in many countries worldwide (Ebbeling, Pawlak, \& Ludwig, 2002; Wang \& Lim, 2012). Approximately 20$30 \%$ of children in North America, Europe and parts of the Western Pacific are overweight or obese (Wang \& Lobstein, 2006). Obesity places children at increased risk of physical and psychological health problems (Reilly et al., 2003). Further, overweight and obesity in childhood tends to persist into adulthood and is associated with morbidity and premature death (Reilly \& Kelly, 2011). Although a number of environmental and perinatal factors have been found to underlie childhood obesity (see Ebbeling et al., 2002), increases in children's weight have coincided with declines in active transportation, such as walking, to and from school (Salmon, Timperio, Cleland, \& Venn, 2005). Research shows that active transportation to school is associated with greater levels of physical activity and lower levels of obesity while controlling for diet (Mendoza et al., 2011). Walking to and from school in particular may be a low cost (Rosenberg, Sallis, Conway, Cain, \& McKenzie, 2006), near universally accessible means of reducing children’s weight (Scott, Eves, French, \& Hoppé, 2007) that can be easily integrated into daily routine (Brophy et al., 2011). Investigating key factors known to influence children's walk to school behavior is therefore important to identify how this low-cost, universal means of active transport to school can be promoted.

A review of extant literature suggests that demographic and environmental factors are important in determining whether children walk to and/or from school. Walking to and from school has been found to be less prevalent in girls (Yeung, Wearing, \& Hills, 2008), although some studies report no significant difference between genders (e.g. van der Ploeg, Merom, Corpuz, \& Bauman, 2008). Older children are reported to be more likely to walk to school (Rodriguez \& Vogt, 2009; Spallek, Turner, Spinks, Bain, \& McClure, 2006; Yeung et al., 2008), whilst children from higher socio-economic backgrounds are less likely (Spallek et al., 
Theory of Planned Behavior: Predicting Walking to School

2006). The number of cars owned by the household and the distance to school are other factors frequently reported to negatively impact active transportation to school (Cole, Leslie, Donald, Cerin, \& Owen, 2007; McDonald, 2008; Merom, Tudor-Locke, Bauman, \& Rissel, 2006; Timperio, Crawford, Telford, \& Salmon, 2004; Timperio et al., 2006; Wen et al., 2007). Children who have access to public transport, such as school buses, have also been found to be less likely to walk to and from school (Rodriguez \& Vogt, 2009). In addition to demographic factors, parental concern or perceived risk with regard to road safety and unwelcome approaches by strangers has also been found to reduce the instance of children walking to and/or from school (Merom et al., 2006; Timperio et al., 2006). In addition, more children were found to actively commute to school in highly-walkable neighborhoods, which have characteristics like interconnected streets, lower traffic exposure and higher residual densities (Giles-Corti et al., 2011; Napier, Brown, Werner, \& Gallimore, 2011).

Although the aforementioned insights from the literature are undoubtedly valuable, there is a call for further investigation of factors that influence walk to school behavior that may be used to guide policy and interventions (see Trapp et al., 2012) to overcome low walking to and from school prevalence. In particular, application of behavioral models has received less attention in a walk to school context where the majority of studies are atheoretical (exceptions Napier et al., 2011). The Theory of Planned Behavior (TPB) (Azjen, 1991) is a parsimonious behavioral model shown to effectively explain and predict a wide range of health-related behaviors (see Godin \& Kok, 1996; McEachan, Conner, Taylor, \& Lawton, 2011). Accordingly, this paper empirically tests the TPB to understand the relative importance of attitude, subjective norms and perceived behavioral control in determining caregivers' intentions to increase their child's walk to school behavior. Employing existing theory in formative research to identify modifiable behavioral determinants is an established approach (Evans, 2006; Lefebvre, 2011) shown to increase the effectiveness of interventions 
Theory of Planned Behavior: Predicting Walking to School

encouraging healthy behavior (e.g. Carins \& Rundle-Thiele, 2013; Gordon, McDermott, Stead, \& Angus, 2006) such as walking to and from school.

Consequently, the current study contributes to the literature in two main ways. First, as a point of departure from extant literature on walking to and/or from school, this research builds on the theoretical understanding of factors that influence walk to school behavior and their relative importance through application of the TPB. This addresses the call for further investigation of factors that influence children walking to and/or from school (see Trapp et al., 2012). Second, the current study also addresses the call for more critical evaluation of theory prior to its use in social marketing interventions (Peattie \& Peattie, 2012). Specifically, this paper tests the capacity of the TPB to explain walk to school behavior and as such, will provide insight as to the usefulness of TPB as a basis for designing interventions to encourage children to walk to and from school.

We organize the paper as follows. First, we provide a review of the conceptual framework and hypotheses that form the basis of the research. Next, the methodological approach of the study is outlined. Last, we present the results and their implications, as well as the limitations of the current study.

\section{Conceptual Framework: Theory of Planned Behavior}

The TPB has been applied to a wide range of health behaviors, including physical activity, smoking cessation, drinking moderation, safer sex and cancer screening (see Godin \& Kok, 1996; McEachan et al., 2011). Overall, the TPB explains and predicts health behaviors well. In one meta-analysis, the TPB explained an average of $41 \%$ of the variance in behavioral intentions and 34\% in behavior (Godin \& Kok, 1996). This is supported by a more recent meta-analysis, which demonstrated that the model explained $44.3 \%$ of the variance in intentions and 19.3\% in behavior (McEachan et al., 2011). 
Theory of Planned Behavior: Predicting Walking to School

In particular, the TPB has been widely applied to improve understanding of the determinants of physical activity for adults (Scott et al., 2007). A meta-analysis across 72 studies demonstrated the explanatory power of TPB for this type of health behavior (Hagger, Chatzizarantis, \& Biddle, 2002). The meta-analysis also showed that the TPB explains significantly more variance in physical activity intentions and behaviors than its predecessor, Theory of Reasoned Action (Fishbein \& Ajzen, 1975). Since this meta-analysis, Rhodes and Courneya (2003) have found that the ТPB explained 32\% of the variance in adults' intentions to exercise and $28 \%$ of exercise behavior, with the strongest predictors in the model being attitude and perceived behavioral control.

However, fewer studies employ the TPB to explain specific exercise behaviors such as walking (Scott et al., 2007). Scott et al. (2007) identified that the TPB explained 22\% and $45 \%$ of the variance in adults' intention to walk in two studies. This result is similar to the study by Eves, Hoppé, and McLaren (2003), which found the TPB explained 17.5\% in the intention to engage in walking behavior. Of note, despite the TPB's predictive validity, it has received criticism for not providing explicit guidance for behavior change strategy (McEachan et al., 2011). Nonetheless, given the model's parsimony and subsequent ease of application, it is unsurprising that interventions designed to promote walking based on the TPB have been found to be effective (Darker, French, Eves \& Sniehotta, 2010; French, Stevenson, \& Michie, 2012).

To the knowledge of the authors, however, the TPB has not yet been employed to investigate walk to school behavior. It is important to test the applicability of this sociocognitive framework within this behavioral domain given the variation evident in the TPB's predictive validity, as well as the relative importance of its predictors, across health behaviors (see Godin \& Kok, 1995; McEachan et al., 2011). Consequently, to extend knowledge in this 
Theory of Planned Behavior: Predicting Walking to School

field, this research applies the TPB to explain caregivers' intention to increase the number of times their children walk to and/or from school.

\section{Hypotheses}

The TPB is built upon the propositions contained within the Theory of Reasoned Action (TRA) (Fishbein \& Ajzen, 1975). Research shows the TRA successfully predicts voluntary behavior based on the behavioral intention of the individual (see Symons Downs \& Hausenblas, 2005; Sheppard, Hartwick, \& Warsaw, 1988). Behavioral intentions “capture the motivational factors that influence a behavior; they are indicators of how hard people are willing to try, of how much effort they are planning to exert, in order to perform the behavior” (Ajzen, 1991, p. 181). In turn, behavioral intention is jointly determined by attitude and subjective norms (Fishbein \& Ajzen, 1975). Attitude is a tendency to evaluate or appraise a behavior favorably or unfavorably (Ajzen, 1991). Attitude comprises both instrumental (i.e. belief-based) and affective (i.e. emotion-based) components (French et al., 2005; Verplanken et al., 1998). Both components have been shown to positively influence intentions toward physical activity generally (e.g. French et al., 2005; Rhodes \& Courneya, 2003) and walking behaviors in adults (Rhodes, Brown, \& McIntyre, 2006). Consequently, it is hypothesized:

$\mathrm{H}_{1}$ : Instrumental attitude will have a positive effect on caregivers' intentions to increase walk to school behavior for a child in their care.

$\mathrm{H}_{2}$ : Affective attitude will have a positive effect on caregivers' intentions to increase walk to school behavior for a child in their care.

Subjective norms, as conceptualized by the TPB and subsequent attitudinal theories, relate to the individual's perception of whether important reference groups support or reject 
Theory of Planned Behavior: Predicting Walking to School

the behavior (Ajzen, 1991). Specifically, subjective norms are formed by an individual's perception of the normative beliefs held by important others towards the behavior together with the extent to which the individual is motivated to comply with these normative beliefs (Manning, 2009). The TPB specifies that the higher the perceived social support for a behavior, the more likely an individual will intend to perform the behavior. Subjective norms have been shown to positively influence intentions toward physical activity in general (Rhodes \& Courneya, 2003) and walking in adults (Scott et al., 2007). Accordingly, it is hypothesized:

$\mathrm{H}_{3}$ : Subjective norms will have a positive effect on caregivers' intentions to increase walk to school behavior for a child in their care.

The TPB extends the TRA by taking into account the effects of individuals’ perceived behavioral control, in addition to attitude and subjective norms, on behavior not under complete volitional control (Ajzen, 1991). Perceived behavioral control refers to "peoples' perception of the ease or difficulty of performing the behavior of interest” (Ajzen, 1991, p.183). It reflects individuals’ belief regarding their access to external resources and opportunities needed to perform a behavior. Perceived behavioral control is proposed to influence behavior positively indirectly through the intention to perform the behavior (Ajzen, 1991). It has been shown to positively influence intentions toward physical activity in general (Eves et al., 2003) and walking in adults (Scott et al., 2007). Consequently, it is hypothesized:

$\mathrm{H}_{4}$ : Perceived behavioral control will have a positive effect on caregivers' intentions to increase walk to school behavior for a child in their care. 
Theory of Planned Behavior: Predicting Walking to School

\section{Method}

\section{Target population}

The target population for this research was caregivers (e.g. parents, grandparents, etc.) responsible for getting a primary school child to and/or from school. This study focused on primary school children, typically aged between five and 12 years old, on the basis that lifelong physical activity patterns are established in childhood and as such, early childhood intervention is considered an important approach to achieving long term improvements in health (Faulkner, Buliung, Flora, \& Fusco, 2009). It was decided to target caregivers, rather than children, given parental control over younger children’s transportation to school (Carver, Timperio, Hesketh, \& Crawford, 2010).

\section{Online Survey}

An online survey was used to collect data. Online advertising was used to disseminate the survey through multiple channels, including Facebook and Twitter. The online survey comprised previously validated scales (items and their origin in the literature are outlined in Appendix 1) and was pre-tested via an informal expert review with seven social marketing researchers. On the basis of feedback, the readability of the introduction to the survey was improved and the ordering of some questions altered. The survey items were divided across pages to encourage survey pacing and decrease the likelihood of respondents missing information by scrolling as per the recommendation of Malhotra (2008). The survey took approximately 10 minutes to complete and respondents were offered the equal chance of winning one of twenty AUS\$30 gift cards for their participation.

\section{Sample}

We collected a purposive sample of 512 caregivers in Victoria, Australia. After data cleaning, including listwise deletion of cases with missing values and the removal of six multivariate outliers, a final sample size of 432 was achieved, meeting the minimum 
Theory of Planned Behavior: Predicting Walking to School

requirement $(n=200)$ for SEM (Kline, 2005). Given the data was missing completely at random (Little’s MCAR test >.05), listwise deletion of missing data was used since it does not introduce any bias into the parameter estimates (Allison, 2003). The sample comprised mostly employed (61.8\%) mothers (86.3\%) aged between 35 to 44 years old (55.4\%). Fifty percent of the sample reported their child walked to or from school at least once a week, with approximately $20 \%$ walking to or from school five days a week. These rates are higher than a study conducted in New South Wales, Australia, where the percentage of children walking to school aged five to 9 years and 10 to 14 years was $25.5 \%$ and $21.1 \%$ respectively (van der Ploeg et al., 2008). Another study conducted in Perth, Australia, showed that the percentage of children aged nine to 13 years that walked to school more than 6 times a week was $25.9 \%$ for girls and 28.8\% for boys (Trapp et al., 2012).

\section{Analysis}

First, we examined the data set for multivariate normality, as well as the presence of outliers and missing values. Following this, the data were analyzed using structural equation modeling (SEM). ML Bootstrap estimation, with 1000 samples and 95\% bias-corrected confidence intervals, was applied in AMOS version 18 given multivariate non-normality of the data in accordance with the recommendation of Byrne (2001). The two-stage SEM approach proposed by Anderson and Gerbing (1988) was employed. First, the measurement model was examined for discriminate and convergent validity, and reliability. Following this, the hypotheses were tested through a full structural model.

\section{Results}

\section{Measurement Model}

The measurement model comprised of 15 observed variables reflecting five factors: Affective Attitude, Instrumental Attitude, Perceived Behavioral Control, Subjective Norms and Intention. It demonstrated close fit to the data: $\chi^{2}(80, \mathrm{n}=432)=129.422$, Bollen-Stine $p$ 
Theory of Planned Behavior: Predicting Walking to School

$<.05 ; \chi^{2} / \mathrm{df}=1.618 ; \mathrm{CFI}=.994 ; \mathrm{TLI}=.992 ; \mathrm{RMSEA}=.038 ;$ and SRMR $=.0313$. The RMSEA is $<.05$ and the $90 \%$ confidence intervals range between 0 and .08 , indicating close fit (Browne \& Cudeck, 1993). The SRMR is less than .05 (Schumacker \& Lomax, 2010), and the CFI and TLI both exceed .95 (Hu \& Bentler, 1999), also indicating good fit with the data. Further, the standardized factor loadings were all significant and above .70 (Kline, 2005), with the exception of one Perceived Behavioral Control item which was close $(\Lambda=.692, p<$ .05). The observed variables’ squared multiple correlations $\left(\mathrm{R}^{2}\right)$ all exceeded .50 (Kline, 2005), with the exception of the same Perceived Behavioral Control item which again closely approached the cutoff $\left(\mathrm{R}^{2}=.479\right)$. This item was retained on the basis of the principle that modifications to models should be done sparingly and only when theoretically plausible (Jackson, Gillaspy, \& Pur-Stephenson, 2009)

Table 1 summarizes the measurement model's reliability and validity information. All Cronbach’s Alpha coefficients (see Table 1) exceeded .70 (Nunnally \& Bernstein, 1994). This demonstrates the items reflecting the latent factors are internally consistent. Convergent validity was established since the composite reliabilities for each construct exceeded the recommended threshold of .70 and the average variance extracted (AVE) for each construct exceeded .50 (Hair, Black, \& Babin, 2010). Discriminant validity was assessed using the procedure of Fornell and Larcker (1981). Since the squared correlation between each pair of constructs was less than the corresponding AVEs, this provides evidence of discriminant validity. Moreover, since cross loadings are not included in the measurement model and the model demonstrates good fit with the data, this also suggests the constructs are adequately differentiated (Hair et al., 2010).

Insert Table 1 here. 
Theory of Planned Behavior: Predicting Walking to School

\section{Structural Model}

The model fit indices indicate the structural model fits the data closely. While the $\chi^{2}$ was significant $\left[\chi^{2}(80, \mathrm{n}=432)=129.422\right.$, Bollen-Stine $\left.p<.05\right]$, it fits the data closely $\left[\chi^{2} / \mathrm{df}\right.$ $=1.618 ; \mathrm{CFI}=.994 ; \mathrm{TLI}=.992 ; \mathrm{RMSEA}=.038 ;$ and SRMR $=.0313]$. The RMSEA is $<.07$ (Hair et al., 2010) and the 90\% confidence intervals range between 0 and .08, indicating acceptable fit (Wang \& Wang 2010). This is important given stimulation studies show RMSEA performs better than other fit indices (Browne \& Cudeck, 1993) and is among the least affected by sample size (Marsh, Balla, \& Hau 1996). Overall, the hypothesized model accounts for approximately $20 \%\left(\mathrm{R}^{2}=.202\right)$ of the variance in Intention.

Table 2 summarizes the results of the hypotheses testing. The results show that Subjective Norms had the largest positive impact on Intention ( $ß=.355, p=.002$, BC 95\% CI [.263, .459]), supporting $\mathrm{H}_{3}$. This was followed by Perceived Behavioral Control's positive relationship with Intention ( $\left(=.195, p=.002\right.$, BC 95\% CI [.110, .284]), supporting $\mathrm{H}_{4}$. Affective Attitude’s positive impact on Intention closely approached significance ( $ß=.121, p$ $=.051, \mathrm{BC} 95 \% \mathrm{CI}[-.001, .258])$, providing some support for $\mathrm{H}_{2}$. Interestingly, the hypothesis that instrumental attitude has a positive effect on the intention to increase walk to school behavior $\left(\mathrm{H}_{1}\right)$ was not supported. In fact, Instrumental Attitude exhibited a significant, negative impact on Intention ( $ß=-.168, p=.022$, BC 95\% CI [-.295, -.033]).

Insert Table 2 here.

\section{Discussion}

This study employed the TPB to explain caregivers' intention to increase the number of times their child walks to and/or from school. The results indicate that the TPB explains approximately $20 \%$ of caregivers' intention to increase their child's walk to school behavior. 
Theory of Planned Behavior: Predicting Walking to School

This is somewhat below the TPB's explanatory power for intentions to perform other health behaviors (see Godin \& Kok, 1996). However, it is consistent with the results of other studies examining walking behavior in particular (Eves et al., 2003; Scott et al., 2007). This result supports previous research showing the explanatory power of the TPB varies between healthrelated behavior categories (Godin \& Kok, 1995; McEachan et al., 2011) and suggests the degree of variance explained by the model may be associated with the specificity of the behavior being measured in the physical activity domain. Further research, however, is required to test this proposition.

The hypotheses were generally supported. The data show that the more supportive important reference groups were perceived to be toward walking to school, the greater respondents' intention to increase the number of times their child walked to and/or from school. In fact, subjective norms were the most powerful predictor in the model. This result was unexpected given previous research examining adults' intention to increase their walking behavior consistently report subjective norms to be the weakest predictor in the TPB (Eves et al., 2003; Scott et al., 2007). This is mirrored in the more general literature, which suggests that subjective norms often exert limited influence on behavioral intentions (White, Smith, Terry, Greenslade, \& McKimmie, 2009), particularly toward health behaviors (Godwin \& Kok, 1996; Hagger et al., 2002). This result may be attributable to stronger social norms surrounding choices related to children. It is also consistent with the Fishbein and Ajzen’s (1975) assertion that the relative impact of subjective norms will vary across contexts.

Whilst instrumental attitude influenced caregivers' intentions to increase their child's walk to school behavior consistent with other health behaviors (Lawton, Conner, \& McEachan, 2009), the relationship between affective attitude and behavioral intentions approached, but did not achieve, statistical significance. The questionable contribution of affective attitude to explaining behavioral intentions is consistent with previous applications 
Theory of Planned Behavior: Predicting Walking to School

of the TPB to walking behavior (Eves et al., 2003; Scott et al., 2007). This is interesting since measures of affective attitude are often more predictive of intention than instrumental attitude on the basis that whilst most people think that exercise is good for them, whether or not people enjoy exercise is often more variable (French et al., 2005). Further in contrast to previous research, this study found instrumental attitude exhibited a negative association with behavioral intentions. This result suggests that the more positive caregivers' beliefs are about walking to school, the less likely they are to intend to increase the number of times their child walks to and/or from school. This highlights the need for replication to validate this finding and may present an opportunity for further research to investigate this counterintuitive association.

Last, the results of this study support a positive relationship between perceived behavioral control and behavioral intentions. Caregivers' who felt more in control of whether or not their child walked to and/or from school were more likely to intend to increase the number of times he/she performed this behavior. Interestingly, in a previous study examining adults' intention to increase their own walking behavior, perceived behavioral control was the most significant predictor in the TPB (Scott et al., 2007). In this study, perceived behavioral control is less important than subjective norms in explaining caregivers' intention to increase their child's walking behavior.

\section{Implications}

\section{Theoretical Implications}

This paper furthers theoretical understanding of the determinants of walk to school behavior through application of the TPB. It demonstrates that there is room for improvement of the TPB in terms of its capacity to explain and predict caregivers' behavioral intentions to increase the number of times their child walks to and/or from school. One avenue for future 
Theory of Planned Behavior: Predicting Walking to School

research is thus to deepen or broaden the TPB with relevant constructs that make a significant, unique contribution to explaining behavioral intentions. Extant literature suggests, for instance, that parents' level of perceived risk influences their intention to permit their child to walk to and/from school (Merom et al., 2006; Timperio et al., 2006). By integrating the influence of other determinants, such as perceived risk, understanding of the relative importance of these factors on walk to school behavior can be improved.

More generally, this paper contributes to the social marketing theory by providing empirical support for the need to validate theoretical frameworks within the behavioral domain of interest through formative research (Evans, 2006; Lefebvre, 2011). This is highlighted by the fact that this study found key differences in the relative importance of the TPB predictors across two arguably related types of behavior: adults’ walking behavior and children's walk to school behavior. This finding also supports Peattie and Peattie’s (2012) argument for the critical evaluation of theory prior to its use in social marketing intervention (Peattie \& Peattie, 2012).

\section{Implications for Social and Health Marketers}

This paper contributes to practice by highlighting the need for caution in employing theoretical frameworks in the development of interventions without first establishing empirically their applicability, and the manner in which they operate, within the behavioral domain of interest. In particular, this research suggests the need to leverage subjective norms, the strongest predictor of walk to school intentions to effect walking to and from school behavior change. In targeting caregivers, marketers need to develop or augment their perception that important others, such as friends and family, approve of children walking to school. Further, the findings suggest that marketers should aim to improve caregivers’ perceived control over their child's walk to school behavior. In doing so, marketers could 
Theory of Planned Behavior: Predicting Walking to School

emphasize the time and cost savings of walking to school, particularly in metropolitan and urban areas with higher levels of school traffic.

\section{Limitations and Future Research}

Although this paper improves the theoretical understanding of the determinants of caregivers' intention to increase the number of times their child walks to and/or from school, it possesses several limitations that must be acknowledged and that represent avenues for future research. First, this study does not measure actual behavior. Although, behavioral intentions have been found to be a good predictor of actual behavior (Armitage \& Conner, 2001; Sheppard et al., 1989; Sutton, 1998), specifically exercise behavior (Symons Downs \& Hausenblas, 2005), it may be useful for future research to include a measure of actual or selfreported walking behavior. Further, work should also be conducted to improve the generalizability of this research given the non-probability convenience sample employed in this online study. In addition, as indicated by the amount of variance explained in behavioral intentions, this study may have missed other important determinants of caregivers' intentions to increase the number of times their child walk to and/or from school by focusing exclusively on testing the TPB. As previously mentioned, future research could investigate augmenting the TPB to improve its explanatory power within this domain. For instance, currently the TPB only examines injunctive, as opposed to descriptive, norms. That is, the conceptualization of subjective norms in the TPB is aligned with that of injunctive norms, which involve perceptions of "what constitutes morally approved or disapproved conduct” (Cialdini, Reno, \& Kallgren, 1990, p. 1015) as opposed to descriptive norms, which involve perceptions of "what is commonly done in a given situation” (Schultz, Nolan, Cialdini, Goldstein, \& Griskevicius, 2007, p. 430). The literature supports accounting for descriptive norms in addition to the injunctive norms (e.g. Rivis \& Sheeran, 2003), particularly since both types of 
Theory of Planned Behavior: Predicting Walking to School

norms have been shown to positively influence health behaviors (Rhodes \& Courneya, 2003). Extending the TPB with descriptive norms may therefore represent an important avenue for future research in this domain, especially considering the important role that norms played in explaining walk to school intentions within this study.

\section{Conclusion}

This study employed a behavioral model, the TPB, to improve understanding of the determinants of walk to school behavior as called for by the literature (see Trapp et al., 2012). In particular, it investigated the relative importance of subjective norms, attitude and perceived behavioral control in influencing caregivers' decision to increase the number of times their children walk to and/or from school. Although the results indicated that there is room for improvement in predicting this decision, subjective norms were found to be particularly important in influencing whether caregivers' intended to increase their children's walk to school behavior. This result contrasts with literature examining adults' walking behavior, supporting the argument for the validation, through formative research, of theoretical frameworks within the behavioral domain of interest prior to their application in intervention and policy development. In summary, this study provides a further step toward improved understanding of the determinants of a cost-effective and accessible health behavior, walking to school, which may play an instrumental part in a wholistic strategy to address the public health crisis that is childhood obesity.

\section{Acknowledgements}

The Victorian Health Promotion Foundation (VicHealth) funded and supported this research. The authors wish to acknowledge research assistance provided during the research design and data collection stages of this project. 
Theory of Planned Behavior: Predicting Walking to School

\section{References}

Ajzen, I. (1991). The theory of planned behaviour. Organizational Behavior and Human Decision Processes, 50, 179-211. Retrieved from http://dx.doi.org.libraryproxy.griffith.edu.au/10.1016/0749-5978(91)90020-T

Allison, P. (2003). Missing data techniques for structural equation modelling. Journal of Abnormal Psychology, 112(4), 545-557. doi:10.1037/0021-843X.112.4.545

Anderson, J. C., \& Gerbing, D. W. (1991). Predicting the performance of measures in a confirmatory factor analysis with a pretest assessment of their substantive validities. Journal of Applied Psychology, 76, 732-740. doi:10.1037/00219010.76.5.732

Armitage, C., \& Conner, M. (2001). Efficacy of the theory of planned behaviour: A metaanalytic review. British Journal of Social Psychology, 40, 471-499. doi:10.1348/014466601164939

Brophy, S., Cooksey, R., Lyons, R., Thomas, N., Rodgers, S., \& Gravenor, M. (2011). Parental factors associated with walking to school and participation in organised activities at age 5: Analysis of the Millennium Cohort Study. BMC Public Health, 11, 14-23. doi: 10.1186/1471-2458-11-14

Browne, M. W., \& Cudeck, R. (1993). Alternative ways of assessing model fit. In K. A. Bollen \& J. S. Jong (Eds.), Testing structural equation models (pp. 136-162). Newbury Park, CA: Sage Publications.

Byrne, B. M. (2001). Structural equation modelling with AMOS: Basic concepts, applications, and programming. Mahwah, NJ: Lawrence Erlbaum.

Carins, J. E., \& Rundle-Thiele, S. (2013). Eating for the better: A social marketing review (2000-2012). Public Health Nutrition, May 28, 1-12.

doi:10.1017/S1368980013001365 
Theory of Planned Behavior: Predicting Walking to School

Carver, A., Timperio, A., Hesketh, K., \& Crawford, D. (2010). Are children and adolescents less active if parents restrict their physical activity and active transport due to perceived risk? Social Science \& Medicine, 70, 1799-1805. doi:10.1016/j.socscimed.2010.02.010

Cialdini, R. B., Reno, R. R., \& Kallgren, C. A. (1990). A focus theory of normative conduct: Recycling the concept of norms to reduce littering in public places. Journal of Personality and Social Psychology, 58(6), 1015-1026. doi:10.1037/00223514.58.6.1015

Cole, R., Leslie, E., Donald, M., Cerin, E., \& Owen, N. (2007). Residential proximity to school and the active transport choices of parents. Health Promotion Journal of Australia, 18, 127-134. doi:10.1071/HE07127

Darker, C. D., French, D. P., Eves, F. F., \& Sniehotta, F. F. (2010). An intervention to promote walking amongst the general population based on an 'extended' theory of planned behaviour: A waiting list randomised controlled trial. Psychology \& Health, 25(1), 71-88. doi:10.1080/08870440902893716

Ebbeling, C., Pawlak, D., \& Ludwig, D. (2002). Childhood obesity: Public-health crisis, common sense cure. The Lancet, 360(9331), 473-482. doi:10.1016/S01406736(02)09678-2

Evans, D. W. (2006). How social marketing works in healthcare. British Medical Journal, 332(7551), 1207-1210. doi:10.1136/bmj.332.7551.1207-a

Faulkner, G. E. J., Buliung, R. N., Flora, P. K., \& Fusco, C. (2009). Active school transport, physical activity levels and body weight levels of children and youth: A systematic review. Preventative Medicine, 48, 3-8. doi:10.1016/j.ypmed.2008.10.017

Fishbein, M., \& Ajzen, I. (1975). Belief, attitude, intention and behavior: An introduction to theory and research. Massachusetts: Addision-Wesley Publishing Company Inc. 
Theory of Planned Behavior: Predicting Walking to School

French, D. P., Stevenson, S., \& Michie, S. (2012). An intervention to increase walking required both motivational and volitional components: A replication and extension. Psychology, Health \& Medicine, 17(2), 127-135. doi:10.1080/13548506.2011.592843

French, D. P., Sutton, S., Hennings, S. J., Mitchell, J., Wareham, N. J., Griffin, S., Hardemand, W., \& Kinmonth, L. (2005). The importance of affective beliefs and attitudes in the theory of planned behavior: Predicting intention to increase physical activity. Journal of Applied Social Psychology, 35(9), 1824-1848.

doi:10.1111/j.1559-1816.2005.tb02197.x

Fornell, C., \& Larcker, D. F. (1981). Evaluating structural equation models with unobservable variables and measurement error. Journal of Marketing Research, 18(1), 39-50. Retrieved from http://search.proquest.com.libraryproxy.griffith.edu.au/docview/235226668?accoun tid $=14543$

Giles-Corti, B., Wood, G., Pikora, T., Learnihan, V., Bulsara, M., Van Niel, K., Timperio, A., McCormack, G., \& Villanueva, K. (2011). School site and the potential to walk to school: The impact of street connectivity and traffic exposure in school neighborhoods. Health \& Place, 17, 545-550. doi:10.1016/j.healthplace.2010.12.011

Godin, G., \& Kok, G. (1996). The theory of planned behaviour: A review of its applications to health-related behaviors. American Journal of Health Promotion, 11(2), 87-98. Retrieved from: http://dx.doi.org/10.4278/0890-1171-11.2.87

Gordon, R., McDermott, L., Stead, M., \& Angus, K. (2006). The effectiveness of social marketing interventions for health improvement: What is the evidence? Public 
Theory of Planned Behavior: Predicting Walking to School

Health, 120(12), 1133-1139. Retrieved from

http://dx.doi.org/10.1016/j.puhe.2006.10.008

Hagger, M. S., Chatzisarantis, N. L. D., \& Biddle, S. J. H. (2002). A meta-analytic review of the theories of reasoned action and planned behavior in physical activity: Predictive validity and the contribution of additional variables. Journal of Sport \& Exercise Psychology, 24, 3-32. doi:10.1037/0022-0663.95.4.784

Hair, J. F., Black, W. C., Babin, B. J., \& Anderson, R. E. (2010). Multivariate data analysis ( $7^{\text {th }}$ ed.). Upper Saddle River, NJ: Prentice-Hall.

Hu, L. T., \& Bentler, P. M. (1999). Cutoff criteria for fit indices in covariance structure analysis: Conventional criteria versus new alternatives. Structural Equation Modelling, 6(1), 1-55. doi: 10.1080/10705519909540118

Jackson, D., Gillaspy, J., \& Purc-Stephenson, R. (2009). Reporting practices in confirmatory factor analysis: An overview and some recommendations. Psychological Methods, 14, 6-23. doi:10.1037/a0014694

Kline, R. B. (2005). Principles and practice of structural equation modelling ( ${ }^{\text {nd }}$ ed.). New York, NY: The Guilford Press.

Lawton, R., Conner, M., \& McEachan, R. (2009). Desire or reason: Predicting health behaviors from affective and cognitive attitudes. Health Psychology, 28(1), 56-65. doi: $10.1037 / \mathrm{a} 0013424$

Lefebvre, C. R. (2011). An integrative model for social marketing. Journal of Social Marketing, 1(1), 54-72. doi:10.1108/20426761111104437

McDonald, N. C. (2008). Children's mode choice for the school trip: The role of distance and school location in walking to school. Transportation, 35, 23-35. doi:10.1007/s11116-007-9135-7 
Theory of Planned Behavior: Predicting Walking to School

Malhotra, N. K. (2008). Completion time and response order effects in web surveys. Public Opinion Quarterly, 72(5), 914-934. doi:10.1093/poq/nfn050

Manning, M. (2009). The effects of subjective norms on behaviour in the theory of planned behaviour: A meta-analysis. British Journal of Social Psychology, 48, 649-705. doi:10.1348/014466608X393136

Marsh, H. W., Balla, J. R., \& Hau, K. T. (1996). An evaluation of incremental fit indices: A clarification of mathematical and empirical properties. In G. A. Marcoulides \& R. E. Schumacker (Eds.), Advanced structural equation modelling: Issues and techniques (pp. 315-353). Hillsdale, NJ: Lawrence Erlbaum Associates.

McEachan, R., Conner, M., Taylor, N., \& Lawton, R. (2011). Prospective prediction of health-related behaviours with the theory of planned behaviour: A meta-analysis. Health Psychology Review, 5(2), 97-144. doi: 10.1080/17437199.2010.521684

Mendoza, J., Watson, K., Nguyen, N., Cerin, E., Baranowski, T., \& Nicklas, T. (2001). Active commuting to school and association with physical activity and adiposity among US youth. Journal of Physical Activity \& Health, 8(4), 488-495. Retrieved from http://europepmc.org/articles/PMC3115568

Merom, D., Tudor-Locke, C., Bauman, A., \& Rissel, C. (2006). Active commuting to school among NSW primary school children: Implications for public health. Health \& Place, 12, 678-687. doi:10.1016/j.healthplace.2005.09.003

Napier, M. A., Brown, B. B., Werner, C. M., \& Gallimore, J. (2011). Walking to school: Community design and child and parent barriers. Journal of Environmental Psychology, 31, 45-51. doi:10.1016/j.jenvp.2010.04.005

Norman, P., \& Conner, M. (2006). The theory of planned behaviour and binge drinking: Assessing the moderating role of past behaviour within the theory of planned 
Theory of Planned Behavior: Predicting Walking to School

behaviour. British Journal of Health Psychology, 11, 55-70.

doi:10.1348/135910705X43741

Nunnally, J. C., \& Bernstein, I. H. (1994). Psychometric theory (3 ${ }^{\text {rd }}$ ed.). New York, NY: McGraw-Hill.

Peattie, K., \& Peattie, S. (2012). The social marketing mix - A critical review. In G. Hastings, K. Angus, \& C. Bryant, The sage handbook of social marketing (pp. 152-166). London: Sage Publications.

Perugini, M., \& Conner, M. (2000). Predicting and understanding behavioral volitions: The interplay between goals and behaviours. European Journal of Social Psychology, 30, 705-731. doi:10.1002/1099-0992(200009/10)30:5<705::AID-JSP18>3.0.CO;2\#

Reilly, J., \& Kelly, J. (2011). Long-term impact of overweight and obesity in childhood and adolescence on morbidity and premature mortality in adulthood: Systematic review. International Journal of Obesity, 35, 891-898. doi:10.1038/ijo.2010.222

Reilly, J., Methven, E., McDowell, Z., Hacking, B., Alexander, D., Stewart, L., \& Kelnar, C. (2003). Health consequences of obesity. Archives of Disease in Childhood, 88, 448752. doi: 10.1136/adc.88.9.748

Rhodes, R. E., Brown, S. G., \& McIntyre, C. A. (2006). Integrating the perceived neighborhood environment and the theory of planned behavior when predicting walking in a Canadian adult sample. American Journal of Health Promotion, 21(2), 110-118. Retrieved from http://dx.doi.org/10.4278/0890-1171-21.2.110

Rhodes, R. E., \& Courneya, K. S. (2003). Investigating multiple components of attitude, subjective norm, and perceived control: An examination of the theory of planned behaviour in the exercise domain. The British Journal of Social Psychology, 42, 129-146. doi:10.1348/014466603763276162 
Theory of Planned Behavior: Predicting Walking to School

Rivas, A., \& Sheeran, P. (2003). Descriptive norms as an additional predictor in the theory of planned behavior: A meta-analysis. Current Psychology: Developmental, Learning, Personality, Social, 22(3), 218-233. doi:10.1007/s12144-003-1018-2

Rodriguez, A., \& Vogt, C. A. (2009). Demographic, environmental, access and attitude factors that influence walking to school by elementary school-aged children. Journal of School Health, 79(6), 255-261. doi:10.1111/j.1746-1561.2009.00407.x

Rosenberg, D., Sallis, J., Conway, T., Cain, K., \& McKenzie, T. (2006). Active transportation to school over 2 years in relation to weight status and physical activity. Obesity, 14(10), 1771-1776. doi:10.1038/oby.2006.204

Rundle-Thiele, S., Russell-Bennett, R., Leo, C., \& Dietrich, T. (2013). Moderating teen drinking: combining social marketing and education. Health Education, 113.5(2013), 392-406.

doi:http://dx.doi.org.libraryproxy.griffith.edu.au/10.1108/HE-07-2012-0041

Salmon, J., Timperio, A., Cleland, V., \& Venn, A. (2005). Trends in children’s physical activity and weight status in high and low socio-economic areas of Melbourne, Victoria. Australian and New Zealand Journal of Public Health. 29(4), 337-341. doi:10.1111/j.1467-842X.2005.tb00204.x

Schultz, W. P., Nolan, J. M., Cialdini, R. B., Goldstein, N. J., Griskevicius, V. (2007). The constructive, destructive, and reconstructive power of social norms. Psychological Science, 18(5), 429-434. doi:10.1111/j.1467-9280.2007.01917.x

Schumacker, R. E., \& Lomax, R. G. (2010). A beginner's guide to structural equation modeling ( $3^{\text {rd }}$ ed.). USA: Routledge Taylor \& Francis Group.

Scott, E. J., Eves, F. F., French, D. P., \& Hoppé, R. (2007). The theory of planned behaviour predicts self-reports of walking, but does not predict step count. British Journal of Health Psychology, 12, 601-620. doi:10.1348/135910706X160335 
Theory of Planned Behavior: Predicting Walking to School

Sheppard, B. H., Hartwick, J., \& Warsaw, P. R. (1988). The theory of reasoned action: A meta-analysis of past research with recommendations for modifications and future research. Journal of Consumer Research, 15(3), 325-343. Retrieved from http://www.jstor.org/stable/2489467

Spallek, M., Turner, C., Spinks, A., Bain, C., \& McClure, R. (2006). Walking to school: Distribution by age, sex and socio-economic status. Health Promotion Journal of Australia, 17, 134-138. doi:10.1071/HE06134

Sutton, S. (1998). Predicting and explaining intentions and behavior: How well are we doing? Journal of Applied Social Psychology, 28, 1317-1338. doi:10.1111/j.15591816.1998.tb01679.x

Symons Downs, D. S., \& Hausenblas, H. A. (2005). The theories of reasoned action and planned behaviour applied to exercise: A meta-analytic update. Journal of Physical Activity and Health, 2, 76-97. Retrieved from http://connection.ebscohost.com/c/articles/15961250/theories-reasoned-actionplanned-behavior-applied-exercise-meta-analytic-update

Timperio, A., Ball, K., Salmon, J., Roberts, R., Giles-Corti, B., Simmons, D., Baur, L. A., \& Crawford, D. (2006). Personal, family, social, and environmental correlates of active commuting to school. American Journal of Preventative Medicine, 30(1), 4551. doi:10.1016/j.amepre.2005.08.047

Timperio, A., Crawford, D., Telford, A., \& Salmon, J. (2004). Perceptions about the local neighbourhood and walking and cycling among children. Preventative Medicine, 38, 39-47. doi:10.1016/j.ypmed.2003.09.026

Trapp, G. S. A., Giles-Corti, B., Christian, H. E., Bulsara, M., Timperio, A., McCormack, F. R., Villaneuva, K. P. (2012). Increasing children’s physical activity: Individual, 
Theory of Planned Behavior: Predicting Walking to School

social environmental factors associated with walking to and from school. Health Education \& Behavior, 39(2), 172-192. doi:10.1177/1090198111423272

van der Ploeg, H. P., Merom, D., Corpuz, G., \& Bauman, A. (2008). Trends in Australian children traveling to school 1971-2003: Burning petrol or carbohydrates? Preventative Medicine, 46, 60-62. doi:10.1016/j.ypmed.2007.06.002

Verplanken, B., Hofstee, G., \& Janssen, H. (1998). Accessibility of affective versus cognitive components of attitudes. European Journal of Social Psychology, 28, 23-35. doi:10.1002/(SICI)1099-0992(199801/02)28:1<23::AID-EJSP843>3.0.CO;2-Z

Wang, Y., \& Lim, H. (2012). The global childhood obesity epidemic and the association between socio-economic status and childhood obesity. International Review of Psychiatry, 24(3), 176-188. doi:10.3109/09540261.2012.688195

Wang, Y., \& Lobstein, T. (2006). Worldwide trends in childhood overweight and obesity. International Journal of Pediatric Obesity, 1, 11-25. doi:10.1080/17477160600586747

White, K., Smith, J., Terry, D., Greenslade, J., \& McKimmie, B. (2009). Social influence in the theory of planned behavior: The role of descriptive, injunctive and in group norms. British Journal of Social Psychology, 48(1), 135-158. doi:10.1348/014466608X295207

Wen, L. M., Fry, D., Rissel, C., Dirkis, H., Balafas, A., \& Merom, D. (2008). Factors associated with children being driven to school: Implications for walk to school programs. Health Education Research, 23(2), 325-224. doi:10.1093/her/cym043

Yeung, J., Wearing, S., \& Hills, A. (2008). Child transport practices and perceived barriers in active commuting to school. Transportation Research, 42, 895-900. doi:10.1016/j.tra.2007.12.007 
Theory of Planned Behavior: Predicting Walking to School

Table 1

Assessment of the Measurement Model's Reliability and Validity

\begin{tabular}{lccccccc}
\hline Latent factors & $\alpha$ & CR & AVE & 1 & 2 & 3 & 4 \\
\hline 1. Instrumental Attitude & .968 & .969 & .912 & & & & \\
2. Affective Attitude & .939 & .942 & .844 & .613 & & & \\
3. Perceived Behavioral Control & .809 & .824 & .613 & .025 & .024 & & \\
4. Subjective Norms & .883 & .887 & .724 & .059 & .051 & .084 & \\
5. Intention & .995 & .996 & .987 & .002 & .010 & .084 & .158
\end{tabular}

Note. $\alpha$ = Cronbach's Alpha coefficient; $\mathrm{CR}$ = composite reliability coefficient; AVE = average variance extracted. 
Theory of Planned Behavior: Predicting Walking to School

Table 2

Results of Hypotheses Testing

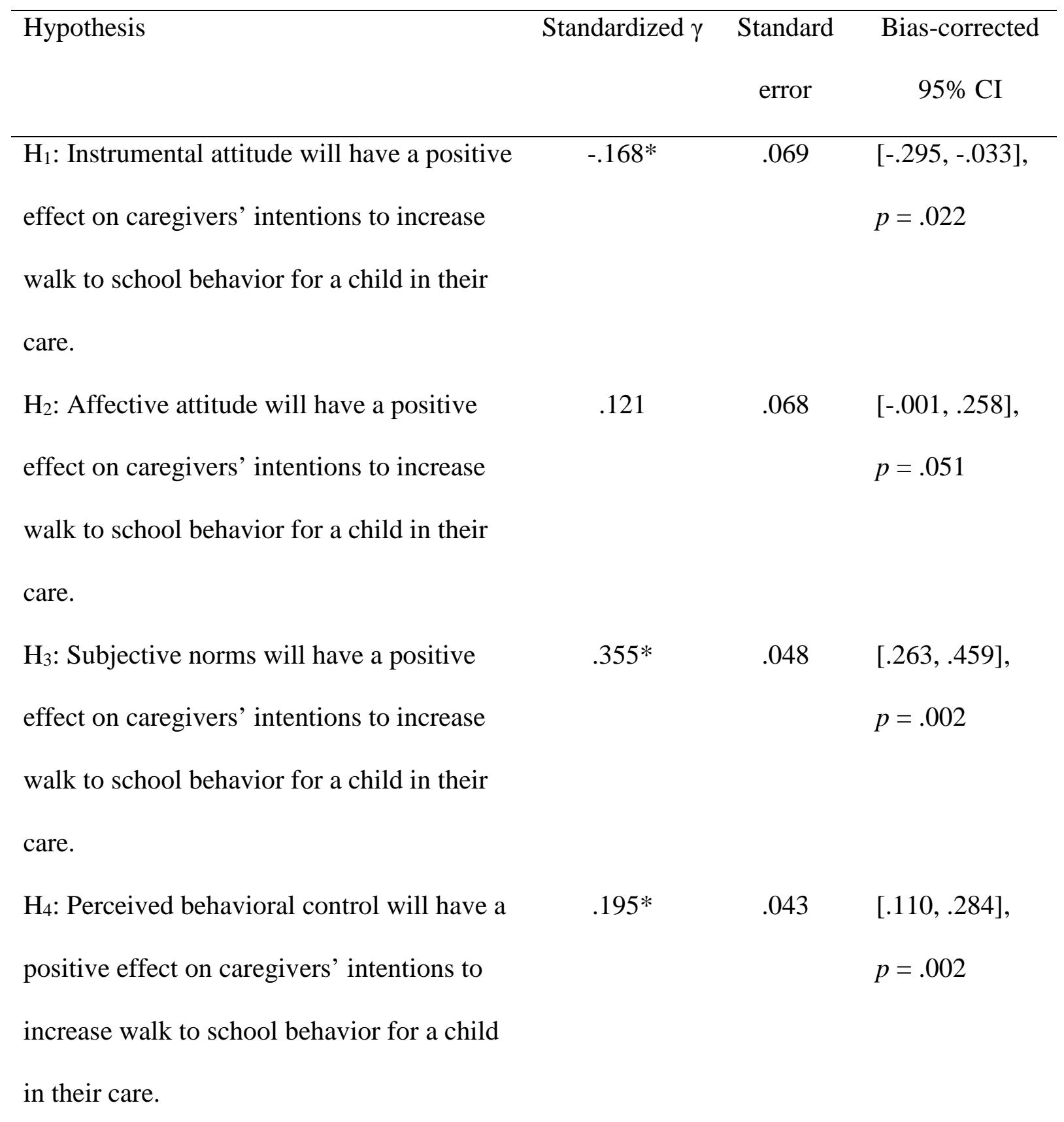

Note. $\mathrm{CI}=$ confidence interval.

$* p<.05$, two-tailed. 
Theory of Planned Behavior: Predicting Walking to School

Appendix 1

Survey Items

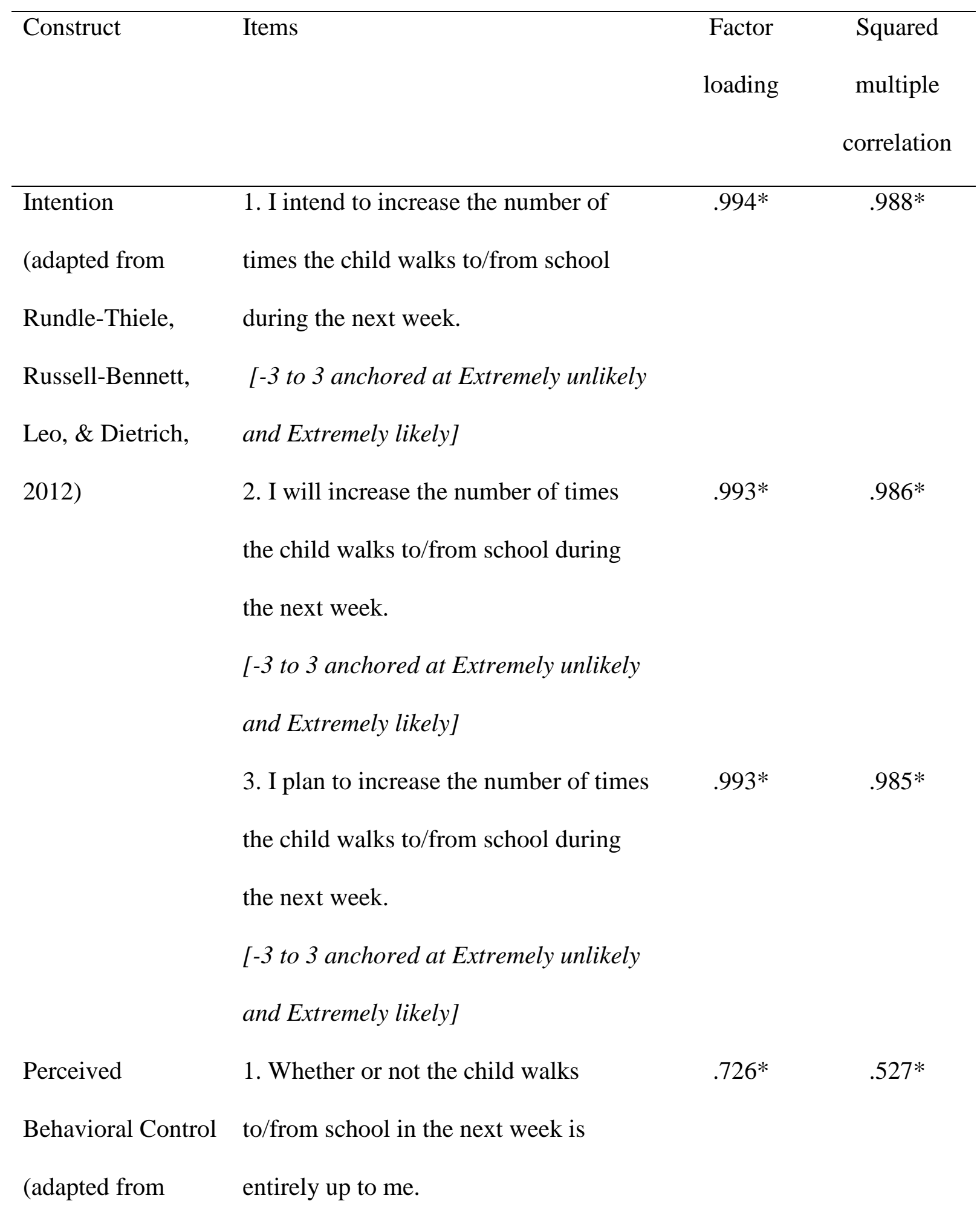


Theory of Planned Behavior: Predicting Walking to School

\begin{tabular}{lccc}
\hline Construct & Items & Factor & Squared \\
& loading & multiple \\
& & correlation
\end{tabular}

Rhodes \& [-3 to 3 anchored at Strongly disagree

Courneya, 2003) and Strongly agree]

2. How much personal control do you

$.912 *$

$.832 *$

feel you have over the child walking

to/from school in the next week?

[-3 to 3 anchored at Very little control

and Complete control]

3. How much do you feel that the child

$.692 *$

$.479 *$

walking to/from school is beyond your

control?

[-3 to 3 anchored at Very much and Not

at all]

Subjective Norms

1. People who are important to me think

$.909 *$

$.827 *$

(adapted from

the child should/should not walk

Perugini \&

to/from school.

Conner, 2000) [-3 to 3 anchored at Should not and

Should]

2. People who are important to me

would disapprove/approve of the child

walking to/from school. 
Theory of Planned Behavior: Predicting Walking to School

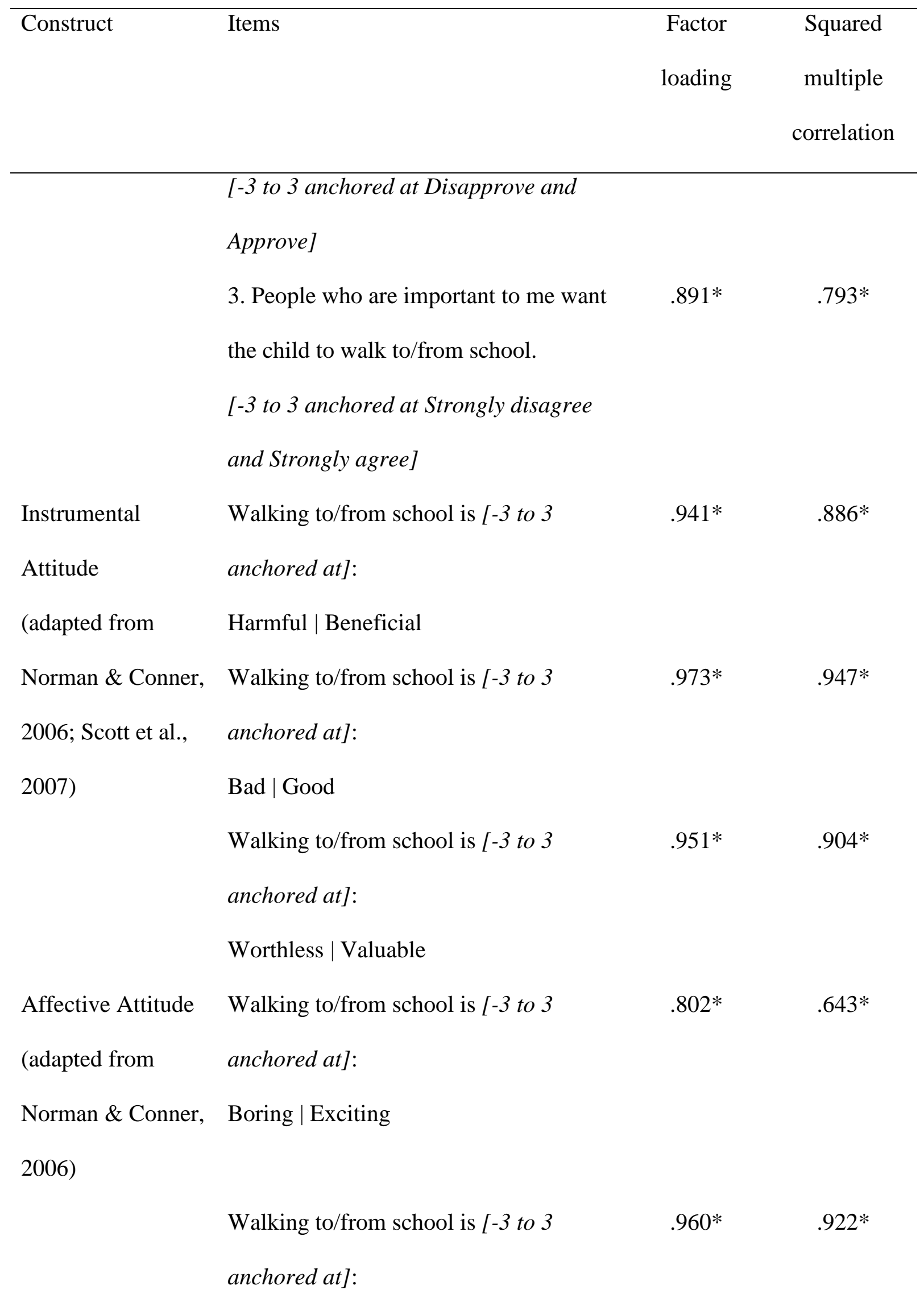


Theory of Planned Behavior: Predicting Walking to School

\begin{tabular}{llc}
\hline Items & Factor & $\begin{array}{c}\text { Squared } \\
\text { multiple } \\
\\
\end{array}$ \\
Unpleasant | Pleasant & $.984^{*}$ & $.968^{*}$ \\
Walking to/from school is $[-3$ to 3 & & \\
anchored at $]:$ & & \\
Unenjoyable | Enjoyable & \\
\hline
\end{tabular}

Note. ${ }^{*} p<.05$, two-tailed. 